\title{
The prevalence of undiagnosed diabetes in non-cardiac surgery patients, an observational study
}

\section{La prévalence de diabète non diagnostiqué chez les patients subissant une chirurgie non cardiaque, une étude observationnelle}

\author{
Basem Abdelmalak, MD · Joseph B. Abdelmalak, MD • Justin Knittel, MD • \\ Eric Christiansen, MBA · Edward Mascha, PhD - Robert Zimmerman, MD • \\ Maged Argalious, MD $\cdot$ Joseph Foss, MD
}

Received: 3 June 2010/Accepted: 15 September 2010/Published online: 5 October 2010

(C) Canadian Anesthesiologists' Society 2010

\begin{abstract}
Purpose Given that preoperative hyperglycemia is associated with poor outcomes and many non-diabetic patients have high plasma glucose (PG) levels, the purpose of our study was to estimate the prevalence of undiagnosed diabetes among non-cardiac surgery patients and to identify predictors of hyperglycemia in non-diabetics.
\end{abstract}

Preliminary results were presented at the American Society of Anesthesiologists Annual Meeting, October 2009 and at the PGA Meeting, December 2009.

B. Abdelmalak, MD $(\varangle) \cdot$ M. Argalious, MD $\cdot$ J. Foss, MD Department of General Anesthesiology, Anesthesiology Institute, Cleveland Clinic, 9500 Euclid Avenue,

Cleveland, OH 44195, USA

e-mail: abdelmb@ccf.org

B. Abdelmalak, MD - E. Mascha, PhD

Department of Outcomes Research, Anesthesiology Institute, Cleveland Clinic, Cleveland, OH, USA

J. B. Abdelmalak, MD

Anesthesiology Institute, Cleveland Clinic, Cleveland, OH, USA

J. Knittel, MD

Department of Anesthesia, Critical Care, and Pain Medicine,

Massachusetts General Hospital, Boston, MA, USA

E. Christiansen, MBA

Registries, Anesthesiology Institute, Cleveland Clinic,

Cleveland, OH, USA

E. Mascha, $\mathrm{PhD}$

Department of Quantitative Health Sciences,

Cleveland Clinic, Cleveland, OH, USA

\section{R. Zimmerman, MD}

Department of Endocrinology, Medicine Institute,

Cleveland Clinic, Cleveland, OH, USA
Methods We included all non-cardiac surgery patients with complete records in the Clinical Database of the Anesthesiology Institute at the Cleveland Clinic during January 2007 to April 2009, and we estimated the prevalence of undiagnosed diabetes and impaired fasting glucose (IFG) among the non-diabetic patients. The mean glucose levels for known diabetics and undiagnosed diabetics were compared using two-tailed Student's t tests, and we assessed the association between PG levels and demographic variables within the non-diabetics.

Results Of the 39,434 patients analyzed, 5,511(14\%) were known diabetics. Of the 33,923 known non-diabetics, 3,426 (10\%) were undiagnosed diabetics and another $3,549(11 \%)$ had IFG. Thus, 6,975 patients (21\%) of the non-diabetic patients presented with abnormally high glucose. Previously undiagnosed diabetics had higher preoperative glucose levels compared with known diabetics, with a mean \pm standard deviation (SD) of $161 \pm 48 \mathrm{vs} 146 \pm 67 \mathrm{mg} \cdot \mathrm{dL}^{-1}(8.9 \pm 2.7 \mathrm{vs}$ $\left.8.1 \pm 3.7 \mathrm{mmoL} \cdot \mathrm{L}^{-1}\right)$, respectively. The difference remained highly significant after adjusting for body mass index, age, sex, and American Society of Anesthesiologists (ASA) physical status $(P<0.001)$. Among non-diabetics, older age, obesity, male sex, and a higher ASA physical status were collectively significant predictors of hyperglycemia, with a c-statistic (95\% confidence interval) of 0.67 (0.66-0.68).

Conclusion A significant proportion of non-cardiac surgery patients have previously undiagnosed diabetes and pre-diabetes. Previously undiagnosed patients have higher fasting glucose levels compared with diabetic patients. Further studies should be conducted to identify the implications of these findings on patient outcomes.

Résumé

Objectif Étant donné que l'hyperglycémie préopératoire est associée à un mauvais pronostic et que de nombreux 
patients non diabétiques présentent des niveaux élevés de glycémie sérique (GS), l'objectif de cette étude était d'estimer la prévalence de diabète non diagnostiqué chez les patients subissant une chirurgie non cardiaque, ainsi que d'identifier les facteurs prédicteurs de l'hyperglycémie chez les patients non diabétiques.

Méthode Entre janvier 2007 et avril 2009, nous avons inclus tous les patients ayant subi une chirurgie non cardiaque dont le dossier était complet dans la base de données d'anesthésie de l'Anesthesiology Institute de la Cleveland Clinic, et nous avons estimé la prévalence de diabète non diagnostiqué et de l'hyperglycémie modérée à jeun (HMJ) chez les patients non diabétiques. Les niveaux moyens de glycémie pour les diabétiques connus et les diabétiques non diagnostiqués ont été comparés à l'aide de tests de Student bilatéraux, et nous avons étudié le lien existant entre les niveaux de GS et les variables démographiques chez les non diabétiques.

Résultats Des 39434 cas analysés, 5511 (14\%) étaient des diabétiques connus. Des 33923 non diabétiques connus, 3426 (10\%) étaient des diabétiques non diagnostiqués, et 3549 (11\%) souffraient d'HMJ. Par conséquent, 6975 patients $(21 \%)$ parmi les non diabétiques présentaient une glycémie anormalement élevée. Les diabétiques non diagnostiqués présentaient des niveaux de glycémie préopératoires plus élevés que les diabétiques connus, avec une moyenne \pm écart type de $161 \pm 48$ contre $146 \pm 67 \mathrm{mg} \cdot d L^{-1}\left(8,9 \pm 2,7\right.$ contre $8,1 \pm 3,7$ mmole $\left.\cdot L^{-1}\right)$, respectivement. La différence est demeurée nettement significative après l'ajustement de l'indice de masse corporelle, de l'âge, du sexe et de l'état physique selon l'American Society of Anesthesiologists (ASA) $(P<0,001)$. Parmi les non diabétiques, l'âge avancé, le sexe masculin et une classification plus élevée du statut physique selon l'ASA étaient d'importants facteurs de prédiction de l'hyperglycémie, avec une c-statistique (intervalle de confiance de $95 \%)$ de 0,67 (0,66 à 0,68).

Conclusion Un pourcentage considérable des patients subissant une chirurgie non cardiaque présentaient un diabète non diagnostiqué et un état prédiabétique. Les patients non diagnostiqués ont des niveaux de glycémie plus élevés à jeun que les patients diabétiques. D'autres études doivent être effectuées afin d'identifier les répercussions de ces conclusions sur le pronostic des patients.

Complications from hyperglycemia continue to be a major drain on our health care system, ${ }^{1}$ and there is increasing evidence that it is associated with an increase in adverse outcomes in the perioperative period. ${ }^{2,3}$

In addition, the American Heart Association has identified hyperglycemia as an independent risk factor for cardiovascular disease in both men and women. ${ }^{4}$
Detrimental outcomes are not exclusive to diabetics. In fact, the risk of adverse outcomes increases progressively along with serum glucose levels regardless of diabetic status. ${ }^{5}$ Clinicians have been monitoring glucose concentrations to avoid either extremely high or low values. Such vigilance is generally given to diabetic patients with less meticulous attention given to non-diabetic patients. Nevertheless, a report from a small sample of surgical patients showed that a high percentage of non-diabetic patients have abnormally high glucose concentrations. ${ }^{6}$ The objectives of our study were threefold: to estimate the prevalence of undiagnosed diabetes among a large sample of patients presenting for non-cardiac surgery in both the ambulatory surgery centre (ASC) and the main operating room (MOR) pavilion; to determine their mean glucose concentration; and to assess the association between baseline demographics and hyperglycemia in nondiabetics.

\section{Methods}

Data for this study were extracted from the Perioperative Health Documentation System of the Anesthesiology Institute at the Cleveland Clinic. This single-centre registry has Institutional Review Board approval to collect perioperative information for quality improvement and for research on patients who present to the operating rooms of Cleveland Clinic's main campus. Data are aggregated from the electronic anesthesia information system and from hospital electronic medical records.

We identified all patients in our database who were presenting for non-cardiac surgery from January 1, 2007 to April 30, 2009, and we excluded those without values for preoperative plasma glucose (PG) concentration or diabetic status. The glucose measurement in the analysis for any given patient was the final value documented in the electronic medical record before surgery, whether obtained on the day of surgery or acquired when the preoperative laboratory tests were drawn in the few days preceding surgery. The determination of glucose concentration was performed in the central laboratories of our institution. We identified whether the surgery was performed in the ASC or MOR and recorded whether or not the patient had a preoperative medical diagnosis of either type of diabetes mellitus (DM). Within the non-diabetics, we defined previously undiagnosed diabetics as patients with no preoperative DM diagnosis on record and with fasting plasma glucose (FPG) concentrations of $\geq 126 \mathrm{mg} \cdot \mathrm{dL}^{-1} \quad\left(7.0 \mathrm{mmoL} \cdot \mathrm{L}^{-1}\right)$; impaired fasting glucose (IFG) is defined as FPG of $\geq 110$ $\left(6.1 \mathrm{mmoL} \cdot \mathrm{L}^{-1}\right)$ and $\left.<126 \mathrm{mg} \cdot \mathrm{dL}^{-1}\left(7.0 \mathrm{mmoL} \cdot \mathrm{L}^{-1}\right)\right)^{7}$

Mean PG concentrations for known diabetics and nondiabetics were compared univariably using two-tailed 
Student's $t$ tests, and analysis of covariance was used after adjusting for body mass index (BMI), age, sex, and American Society of Anesthesiologists (ASA) physical status. Known diabetics and non-diabetics were also compared on the three-category glucose variable of glucose, i.e., $<110 \mathrm{mg} \cdot \mathrm{dL}^{-1}\left(6.1 \mathrm{mmoL} \cdot \mathrm{L}^{-1}\right)$, IFG, or diabetic FPG, using the Cochran-Mantel-Haenszel test.

For non-diabetics, we assessed the univariable associations between the three-category glucose variable and demographic variables using appropriate statistical tests. Multiple comparison adjustments were made using the Holm-Bonferroni approach for binary variables, Dunn's multiple comparison procedure for ordinal ASA physical status, and Tukey's pairwise comparison procedure for age and BMI.

Multivariable logistic regression was used to assess the association between undiagnosed diabetic status (FPG $\geq$ $\left.126 \mathrm{mg} \cdot \mathrm{dL}^{-1}\left[7.0 \mathrm{mmoL} \cdot \mathrm{L}^{-1}\right]\right)$ and patient BMI, age, sex, and ASA physical status among those who did not carry the diagnosis of DM. Prediction accuracy was summarized with a c-statistic and 95\% confidence interval (CI).

The interaction between location (ASC or MOR) and preoperative diabetic status (known diabetics vs previously undiagnosed diabetics) on preoperative glucose was assessed using multiple regression analysis adjusting for BMI, age, sex, and ASA physical status.

For multivariable analyses, we chose a priori to adjust for BMI, age, sex, and ASA physical status, the most obvious potential confounders of the relationship of interest, regardless of their observed statistical significance with the outcome. Data were log transformed to meet regression assumptions, and appropriate adjustments for multiple comparisons were made to preserve the Type I error at 0.05 for each hypothesis. SAS statistical software (SAS Institute Inc., Cary, NC, USA) was used for all analyses.

\section{Results}

There were 47,488 non-cardiac surgery patients in the Anesthesia Clinical Database from January 1, 2007 to April 30, 2009. We excluded 8,054 patients who did not have a preoperative PG value or diabetic status (Figure). Thus, a total of 39,434 patients with diabetic status and preoperative glucose were analyzed. Of these, 5,511 (14\%) were previously diagnosed as having DM. Of the 33,923 nondiabetics, 3,426 (10\%, 95\% CI 9.8-10.4\%) had FPG $\geq 126$ $\mathrm{mg} \cdot \mathrm{dL}^{-1}\left(7.0 \mathrm{mmoL} \cdot \mathrm{L}^{-1}\right.$, previously undiagnosed diabetics), and another $3,549(10.5 \%, 95 \%$ CI 10.1-10.8\%) had FPG $\geq 110 \mathrm{mg} \cdot \mathrm{dL}^{-1}\left(6.1 \mathrm{mmoL} \cdot \mathrm{L}^{-1}\right.$, IFG). Thus a total of 6,975 patients $(21 \%, 95 \%$ CI $20.1-21.0 \%)$ of the nondiabetics presented with $\mathrm{FPG} \geq 110 \mathrm{mg} \cdot \mathrm{dL}^{-1}\left(6.1 \mathrm{mmoL} \cdot \mathrm{L}^{-1}\right)$ (Table 1). As expected, diabetics were more likely to have

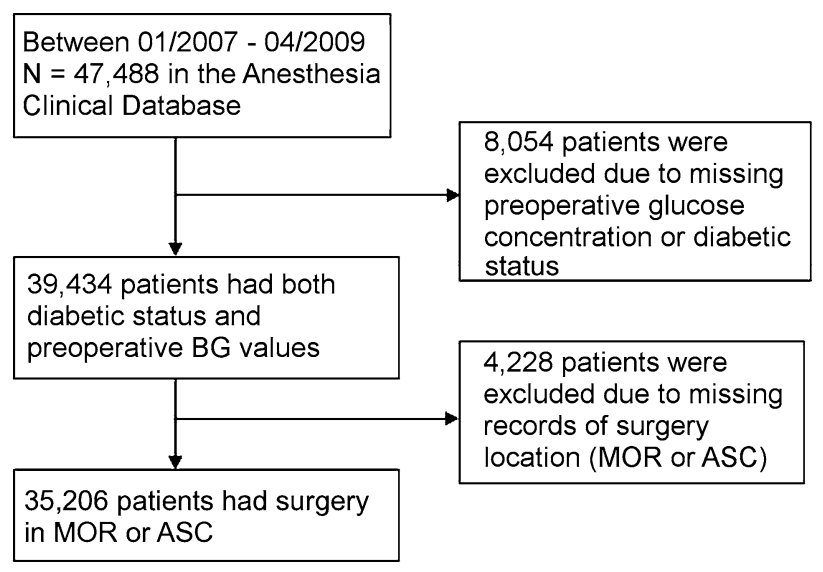

Figure Data processing chart. MOR = main operating room; $\mathrm{ASC}=$ ambulatory surgical centre

higher glucose values and a higher proportion with glucose values $>126 \mathrm{mg} \cdot \mathrm{dL}^{-1}\left(7.0 \mathrm{mmoL} \cdot \mathrm{L}^{-1}\right)(P<0.001) \mathrm{com}-$ pared with non-diabetics.

Compared with known diabetics as a whole, patients with previously undiagnosed DM had considerably higher preoperative glucose values, with FPG of $160.9 \pm 48.1$ $\mathrm{mg} \cdot \mathrm{dL}^{-1}\left(8.9 \pm 2.7 \mathrm{mmoL} \cdot \mathrm{L}^{-1}\right)$ compared with $145.8 \pm$ $67.2 \mathrm{mg} \cdot \mathrm{dL}^{-1}\left(8.1 \pm 3.7 \mathrm{mmoL} \cdot \mathrm{L}^{-1}\right)$ for diabetic patients. The difference remained significant after adjusting for BMI, age, sex, and ASA physical status $(P<0.001)$.

For patients with no history of diabetes, a higher FPG category was associated with older age, and patients with FPG $<110 \mathrm{mg} \cdot \mathrm{dL}^{-1}\left(6.1 \mathrm{mmoL} \cdot \mathrm{L}^{-1}\right)$ had a significantly lower BMI compared with the higher FPG groups (Table 2). Those with FPG $<110 \mathrm{mg} \cdot \mathrm{dL}^{-1}\left(6.1 \mathrm{mmoL} \cdot \mathrm{L}^{-1}\right)$ were more likely to be female, and mean ASA physical status increased with FPG category. All pairwise comparisons between FPG $<110 \mathrm{mg} \cdot \mathrm{dL}^{-1}\left(6.1 \mathrm{mmoL} \cdot \mathrm{L}^{-1}\right)$ and $\mathrm{FPG} \geq 126 \mathrm{mg} \cdot \mathrm{dL}^{-1}$ (7.0 $\left.\mathrm{mmoL} \cdot \mathrm{L}^{-1}\right)$ differed significantly in relation to demographics.

When taken together, BMI, age, sex, and ASA physical status were significant predictors of FPG $\geq 126 \mathrm{mg} \cdot \mathrm{dL}^{-1}$ $\left(7.0 \mathrm{mmoL} \cdot \mathrm{L}^{-1}\right)$ for these patients, with a multivariable $c$-statistic (95\% CI) of 0.67 (0.66-0.68). The odds ratio (95\% $\mathrm{CI})$ of having undiagnosed diabetes was 1.17 (1.13-1.20) with an increase of ten years in age $(P<0.001), 1.12$ (1.09-1.15) with an increase of 5 in BMI $(P<0.001), 0.73$ (0.68-0.80) for females vs males $(P<0.001)$, and $1.81(1.70-1.93)$ with an increase of one ASA category $(P<0.001)$.

Thirty-two thousand, four hundred twenty-eight $(92.1 \%)$ patients had surgery in the MOR, and 2,778 (7.9\%) patients had surgery in the ASC. Among the ASC patients, 13\% presented to surgery with abnormally high glucose levels; $5 \%$ of the previously known not to have diabetes were undiagnosed diabetics, and another $8 \%$ were diagnosed with IFG. 
Table 1 Demographics and preoperative glucose concentration according to diabetic status*

\begin{tabular}{lll}
\hline Factor & Diabetics $(n=5,511)^{\mathrm{a}}$ & Non-diabetics $(n=33,923)^{\mathrm{b}}$ \\
\hline Age $(\mathrm{yr})$ & $63 \pm 13$ & $56 \pm 16$ \\
BMI $\left(\mathrm{kg} \cdot \mathrm{m}^{-2}\right)$ & $33 \pm 9$ & $29 \pm 7$ \\
Female $n(\%)$ & $2,618(48)$ & $18,006(53)$ \\
ASA physical status $n(\%)$ & & $1,677(5)$ \\
I & $6(0.1)$ & $15,441(45.6)$ \\
II & $932(16.9)$ & $14,516(42.8)$ \\
III & $3,794(68.9)$ & $2,176(6.4)$ \\
IV & $768(13.9)$ & $68(0.2)$ \\
V & $10(0.2)$ & $26,948(79)$ \\
Preoperative Glucose concentration $\dagger(\%)$ & & $3,549(11)$ \\
Glucose $<110 \mathrm{mg} \cdot \mathrm{dL}^{-1}\left(6.1 \mathrm{mmoL} \cdot \mathrm{L}^{-1}\right)$ & $1,857(34)$ & $3,426(10)$ \\
Glucose $110-126 \mathrm{mg} \cdot \mathrm{dL}$ & $751(14)$ & \\
Glucose $\geq 126 \mathrm{mg} \cdot \mathrm{dL}{ }^{-1}\left(7.0 \mathrm{mmoL} \cdot \mathrm{L}^{-1}\right)$ & $2,903(53)$ & \\
\hline
\end{tabular}

* Statistics presented as mean \pm standard deviation (SD) and $n(\%)$

$\dagger P<0.001$ from Cochran-Mantel-Haenszel test

${ }^{\text {a }}$ Missing values for age, BMI, and ASA status; $11 \%, 15 \%$, and $0.2 \%$, respectively

${ }^{\mathrm{b}}$ Missing values for age, BMI, and ASA status; $11 \%, 16 \%$, and $0.1 \%$, respectively. BMI = body mass index; ASA $=$ American Society of Anesthesiologists

Table 2 Univariable association between non-diabetic glucose concentration group and demographics

\begin{tabular}{|c|c|c|c|c|}
\hline \multirow[t]{2}{*}{ Factor } & \multicolumn{3}{|c|}{ Glucose concentration $\mathrm{mg} \cdot \mathrm{dL}^{-1}\left(\mathrm{mmoL} \cdot \mathrm{L}^{-1}\right)^{*}$} & \multirow[t]{2}{*}{$P$ value $^{\mathrm{d}}$} \\
\hline & $\begin{array}{l}<110 \mathrm{mg} \cdot \mathrm{dL}^{-1} \\
\left(6.1 \mathrm{mmoL} \cdot \mathrm{L}^{-1}\right) \\
n=26,948^{\mathrm{a}}\end{array}$ & $\begin{array}{l}110-126 \mathrm{mg} \cdot \mathrm{dL}^{-1} \\
\left(6.1-7.0 \mathrm{mmoL} \cdot \mathrm{L}^{-1}\right) \\
n=3,549^{\mathrm{b}}\end{array}$ & $\begin{array}{l}\geq 126 \mathrm{mg} \cdot \mathrm{dL}^{-1} \\
\left(7.0 \mathrm{mmoL} \cdot \mathrm{L}^{-1}\right) \\
n=3,426^{\mathrm{c}}\end{array}$ & \\
\hline Age $(y r)$ & $55 \pm 16$ & $59 \pm 16$ & $61+15$ & $<0.001^{\mathrm{e}}$ \\
\hline $\operatorname{BMI}\left(\mathrm{kg} \cdot \mathrm{m}^{-2}\right)$ & $28 \pm 7$ & $30 \pm 7$ & $30 \pm 8$ & $<0.001^{\mathrm{f}}$ \\
\hline Female $n(\%)$ & $14,857(55)$ & $1,623(46)$ & $1,526(45)$ & $<0.001^{\mathrm{f}}$ \\
\hline ASA physical status $n(\%)$ & & & & $<0.001^{+e}$ \\
\hline I & $1,536(5.7)$ & $89(2.5)$ & $52(1.5)$ & \\
\hline II & $13,134(48.8)$ & $1,338(37.8)$ & $969(28.4)$ & \\
\hline III & $10,894(40.5)$ & $1,782(50.3)$ & $1,840(53.9)$ & \\
\hline IV & $1,338(5.0)$ & $329(9.3)$ & $509(14.9)$ & \\
\hline $\mathrm{V}$ & $20(0.1)$ & $6(0.2)$ & $42(1.2)$ & \\
\hline
\end{tabular}

* Statistics presented as mean \pm standard deviation (SD) and $n(\%)$

${ }^{\text {a }}$ Missing values for age, BMI, and ASA status; $11 \%, 16 \%$, and $0.1 \%$, respectively

b Missing values for age, BMI, and ASA status; $10 \%, 17 \%$, and $0.1 \%$, respectively

${ }^{c}$ Missing values for age, BMI, and ASA status; $10 \%, 20 \%$, and $0.4 \%$, respectively

${ }^{\mathrm{d}}$ Chi square test for categorical variables unless otherwise noted; + Kruskal-Wallis Test

Significant pairwise differences among fasting plasma glucose (FPG) groups:

e FPG $<110$ and FPG $110-126$, FPG $<110$ and FPG $\geq 126$

${ }^{\mathrm{f}}$ FPG $<110$ and FPG $110-126$, FPG $110-126$ and FPG $\geq 126$. Multiple comparison adjustments: Holm-Bonferroni approach was used for sex; Dunn's multiple comparison procedure was used for ASA physical status; and Tukey's method was used for age and BMI

ASA =American Society of Anesthesiologists; BMI = body mass index

In a multiple regression model, Table 3 compares known diabetics with previously undiagnosed diabetics in terms of preoperative FPG, adjusting for location of surgery (MOR vs ASC), sex, BMI, ASA physical status, and age. The overall mean FPG in known diabetics was significantly lower than that of the previously undiagnosed 
Table 3 Regression of preoperative glucose concentration on diabetic status adjusting for type of surgery and demographics

\begin{tabular}{lllll}
\hline $\begin{array}{l}\text { Type of surgical } \\
\text { patients }\end{array}$ & Units & $\begin{array}{l}\text { Known diabetics } \\
n=4,911^{\mathrm{a}} \text { Geometric } \\
\text { Mean }(95 \% \mathrm{CI})\end{array}$ & $\begin{array}{l}\text { Previously undiagnosed } \\
\text { diabetics } n=3,090^{\mathrm{b}} \\
\text { Geometric Mean }(95 \% \mathrm{CI})\end{array}$ & $\begin{array}{l}\text { Ratio of Geometric } \\
\text { Means }(95 \% \mathrm{CI})^{*}\end{array}$ \\
\hline Overall & $\mathrm{mg} \cdot \mathrm{dL}^{-1}$ & $133(132-135)$ & $157(155-158)$ & $0.85(0.84-0.87)$ \\
& $\left(\mathrm{mmoL} \cdot \mathrm{L}^{-1}\right)$ & $7.4(7.3-7.5)$ & $8.7(8.6-8.8)$ & $0.91(0.84-0.99)$ \\
ASC & $\mathrm{mg} \cdot \mathrm{dL}^{-1}$ & $139(133-146)$ & $153(144-164)$ & 0.0001 \\
& $\left(\mathrm{mmoL} \cdot \mathrm{L}^{-1}\right)$ & $7.7(7.4-8.1)$ & $8.5(8.0-9.1)$ & $0.85(0.83-0.86)$ \\
MOR & $\mathrm{mg} \cdot \mathrm{dL}^{-1}$ & $133(131-135)$ & $157(155-158)$ & $<0.001$ \\
\hline
\end{tabular}

${ }^{\mathrm{a}} n=232$ of known diabetics and ${ }^{\mathrm{b}} n=348$ of previously undiagnosed diabetics excluded from the regression model due to missing demographics. * Ratio of means on glucose is known diabetics divided by previously undiagnosed diabetics. Ratio estimates and confidence intervals are adjusted for baseline variables; body mass index $(P=0.07)$, male sex $(P=0.021)$, American Society of Anesthesiologists physical status $(P<0.001)$, and age $(P<0.001)$. The interaction between diabetic status and type of surgical patient was significant at the 0.10 level used for interactions $(P=0.073)$. $\mathrm{CI}=$ confidence interval; ASC $=$ ambulatory surgical centre; $\mathrm{MOR}=$ main operating room

diabetics (ratio of geometric means [CI] 0.85 0.84-0.87; $P<0.001)$. Furthermore, the relationship between diabetic grouping and glucose values depended to some extent on the location of surgery (interaction $P$ value of 0.073 ), although mean glucose levels were higher in previously undiagnosed diabetics than in known diabetics for both ambulatory surgery patients and those presenting for more serious surgery in the MOR.

\section{Discussion}

Our findings indicate that there is a significant proportion $(21 \%)$ of patients presenting for non-cardiac surgery who do not carry the diagnosis of diabetes but are hyperglycemic, and about half of those $(10 \%)$ are undiagnosed diabetics. $^{7}$ The ASC patients, generally viewed as a healthier population, also had a $13 \%$ incidence of hyperglycemia.

It was possible to identify a pattern to help distinguish patients who are more likely to have an abnormally high FPG. Among those who don't carry the diagnosis of DM, older patients, obese patients, and males with a higher ASA physical status were more likely to have hyperglycemia and, therefore, might require closer monitoring. These predictors might prove helpful in deciding where resources should be directed in terms of monitoring glucose concentrations perioperatively, especially in the apparently healthier patients presenting for ambulatory surgery.

Umpierrez et al. have reported a $12 \%$ rate of undiagnosed diabetics in a sample of 2,000 hospital-wide admissions. ${ }^{6}$ They also identified that newly diagnosed hyperglycemia was associated with a higher mortality rate (16\%) when compared with known diabetics (3\%) and normoglycemic patients (1.3\%). Similarly, undiagnosed diabetes and pre-diabetes have been reported in other clinical situations, e.g., in patients with myocardial infarction, ${ }^{8}$ and have been shown to be associated with long-term outcomes. ${ }^{9}$

Hyperglycemia is associated with micro and macro vascular disease, and patients with undiagnosed type 2 diabetes are at a significantly increased risk of obesity, hypertension, coronary artery disease, peripheral vascular disease, and cerebrovascular accidents that can contribute to increased perioperative morbidity and mortality. ${ }^{10}$

Emerging retrospective data are supporting the notion that hyperglycemia is harmful in the perioperative setting. A recent case-control study in the Netherlands examined preoperative blood glucose levels and mortality in noncardiac, non-vascular surgery patients, and findings indicated that preoperative blood glucose levels $>200$ $\mathrm{mg} \cdot \mathrm{dL}^{-1}\left(11.1 \mathrm{mmoL} \cdot \mathrm{L}^{-1}\right)$ were associated with a 2.1 -fold increased risk in overall mortality and a fourfold increased risk in cardiovascular mortality. ${ }^{11}$ The study showed that the risk of mortality in patients with glucose levels from 110 to $200 \mathrm{mg} \cdot \mathrm{dL}^{-1}\left(6.1-11.1 \mathrm{mmoL} \cdot \mathrm{L}^{-1}\right)$ was directly related to glucose concentrations; for every $1 \mathrm{mmoL}$ $\left(18 \mathrm{mg} \cdot \mathrm{dL}^{-1}\right)$ increase in glucose concentration, there was a $19 \%$ increase in the risk of mortality. Another study in Canada showed a direct relationship between glucose concentration and the risk of pulmonary embolism, with up to a fourfold increased risk in patients undergoing total joint replacement with preoperative levels $>200 \mathrm{mg} \cdot \mathrm{dL}^{-1}$ $\left(11.1 \mathrm{mmoL} \cdot \mathrm{L}^{-1}\right){ }^{2}$

In cardiac surgery patients, preoperative glucose concentrations $>110 \mathrm{mg} \cdot \mathrm{dL}^{-1}\left(6.1 \mathrm{mmoL} \cdot \mathrm{L}^{-1}\right)$ have been associated with a longer hospital stay and increased mortality. $^{3}$

The findings of this study confirm the notion that aspects of our preoperative assessment of surgical patients should be re-examined. While it is becoming increasingly apparent that hyperglycemia in the perioperative state leads to poor outcomes, our field lacks definitive guidelines or recommendations for patient blood glucose monitoring and 
management in these cases. This study indicates that we need to be more aware of the patient's preoperative baseline glycemic state. The magnitude and scale of the phenomenon of preoperative hyperglycemia among patients who had no prior diagnosis of diabetes is impressive. For example, an alarmingly large number of patients in our cohort $(3,500)$ had an IFG $>110 \mathrm{mg} \cdot \mathrm{dL}^{-1}\left(6.1 \mathrm{mmoL} \cdot \mathrm{L}^{-1}\right)$ and $<126$ $\mathrm{mg} \cdot \mathrm{dL}^{-1}\left(7.0 \mathrm{mmoL} \cdot \mathrm{L}^{-1}\right)$, while, unsurprisingly, only 750 patients among the known diabetics fell within that range.

The identification of undiagnosed diabetes preoperatively may alter our surgical planning. For example, according to the American College of Cardiologists/American Heart Association guidelines, identifying undiagnosed diabetes would add an additional risk factor to a patient's existing morbidities and may change the approach to surgery in terms of conducting a preoperative cardiac evaluation. ${ }^{12}$

Second, because of the apparent potential risk of undiagnosed diabetes and hyperglycemia in preoperative patients, increased vigilance may result in an increase in the number of patients identified with a new diagnosis of diabetes. This resulting diagnosis has the potential to benefit these patients beyond the perioperative period to their lifelong general state of health. The current evidence suggests that early diagnosis and treatment of type 2 diabetes might well reduce its burden and its complications. ${ }^{7}$

Finally, this study provides additional data to the debate regarding perioperative glucose management. It presents a challenge for clinicians and researchers to conduct more trials in order to 1) confirm whether it is indeed harmful to be hyperglycemic in the perioperative period; 2) prove (or disprove) whether it is beneficial to aim an intervention at controlling the glucose concentrations in the perioperative period; 3) identify what would constitute a safer glucose level in the perioperative period, learning from the unsettled debate of glucose control in the intensive care unit ${ }^{13}$ and lastly 4) determine the surgical procedures and subset of patients that would benefit from the favourable effects, if any, of glucose control.

Some of this work has already begun. The AACE (American Academy of Clinical Endocrinologists) and the ADA (American Diabetes Association) have published a consensus statement based on the NICE-SUGAR trial suggesting that the optimal glucose level should range from $140-180 \mathrm{mg} \cdot \mathrm{dL}^{-1}\left(7.9-10.0 \mathrm{mmoL} \cdot \mathrm{L}^{-1}\right){ }^{14,15}$ This range, which may be considered rather broad, was probably proposed because of the unacceptably high risk of hypoglycemia observed in association with tighter goals. ${ }^{16,17}$ The best current evidence for intraoperative glucose control in non-cardiac surgery recommends a range from 110-150 $\mathrm{mg} \cdot \mathrm{dL}^{-1}\left(6.1-8.3 \mathrm{mmoL} \cdot \mathrm{L}^{-1}\right){ }^{18} \mathrm{We}$ are expecting the results from one arm of the Dexamethasone, Light Anesthesia, and Tight Glucose Control (DeLiT) Trial, which is evaluating levels of intraoperative glucose control (i.e., $80-110 \mathrm{mg} \cdot \mathrm{dL}^{-1}$ vs $180-200 \mathrm{mg} \cdot \mathrm{dL}^{-1}$ [5.0-6.1 $\mathrm{mmoL} \cdot \mathrm{L}^{-1}$ vs $10-11.1 \mathrm{mmoL} \cdot \mathrm{L}^{-1}$, respectively]) in major non-cardiac surgery. ${ }^{19}$

This is a retrospective review of our database, and, as such, there is the potential that unavailable data might confound the relationships of interest. Specifically, we excluded patients who did not have a preoperative blood glucose determination available. While this factor may overestimate the prevalence of undiagnosed diabetes, presumably these patients have enjoyed good health and/or have undergone a minor surgical procedure that did not indicate the need for a preoperative check of their blood glucose concentration. Only a single measurement of glucose concentration is utilized to determine a diabetes diagnosis $v s$ the traditional approach of two measurements at two separate occasions; however, a single measurement is the recommended methodology for diagnosing diabetes in epidemiologic studies such as ours. ${ }^{7}$ Furthermore, we did not have hemoglobin A1C values available, so the degree of chronic change in the patients' glucose concentrations is unknown. It is possible that preoperative HA1c levels may provide more definitive evidence of the number of patients who present for surgery with undiagnosed diabetes, and further work is needed in this regard.

The generalizability of our results is limited by the fact that our cohort appears to be composed of patients of higher than average risk. Indeed, approximately half of our patients were ASA physical status III or above. It would be interesting to determine if similar results would be reproduced in different patient populations.

At this point, we are unable to report on the impact of these findings on outcomes, as the complicated analysis of data is in progress and will be reported in a future publication. However, the purpose of this manuscript is to promote awareness of the high proportion of hyperglycemic non-diabetic surgical patients. It is our hope that this matter will receive extra attention and better monitoring and that future research on perioperative glucose control will be directed at this particular group of patients. Also, this may explain, to some extent, our rationale for excluding cardiac surgery patients, as these patients already enjoy more attention from researchers as well as very close monitoring of the pre, intra, and postoperative laboratory blood glucose values through frequent arterial blood gas determinations. While this decision may result in underestimating the prevalence of undiagnosed diabetics in surgical patients in general, it might also dilute our message of focusing on non-cardiac surgery patients.

In conclusion, a significant proportion of non-cardiac surgery patients are undiagnosed diabetics with fasting blood glucose levels even higher than diabetics. Among non-diabetics, the following factors independently predicted hyperglycemia: older age, obesity, male sex, and 
higher ASA physical status. The current guidelines for monitoring preoperative glucose in non-diabetic patients should be revisited. Further studies should be conducted to identify the implications of these findings on patient outcomes.

Funding This study was supported by internal funds only.

Competing interests None of the authors has any competing interest.

\section{References}

1. Narayan KM, Boyle JP, Thompson TJ, Sorensen SW, Williamson $D F$. Lifetime risk for diabetes mellitus in the United States. JAMA 2003; 290: 1884-90.

2. Mraovic B, Hipszer BR, Epstein RH, Pequignot EC, Parvizi J, Joseph JI. Preadmission hyperglycemia is an independent risk factor for in-hospital symptomatic pulmonary embolism after major orthopedic surgery. J Arthroplasty 2010; 25: 64-70.

3. De Witte JL, Alegret C, Sessler DI, Cammu G. Preoperative alprazolam reduces anxiety in ambulatory surgery patients: a comparison with oral midazolam. Anesth Analg 2002; 95: 1601-6.

4. Bennett EJ, Patel KP, Grundy EM. Neonatal temperature and surgery. Anesthesiology 1977; 46: 303-4.

5. Gerstein HC, Pais P, Pogue J, Yusuf S. Relationship of glucose and insulin levels to the risk of myocardial infarction: a casecontrol study. J Am Coll Cardiol 1999; 33: 612-9.

6. Umpierrez GE, Isaacs SD, Bazargan N, You X, Thaler LM, Kitabchi $A E$. Hyperglycemia: an independent marker of in-hospital mortality in patients with undiagnosed diabetes. J Clin Endocrinol Metab 2002; 87: 978-82.

7. Van de Velde M. Interventional neuroradiology. Curr Opin Anaesthesiol 2003; 16: 417-20.

8. Norhammar A, Tenerz A, Nilsson G, et al. Glucose metabolism in patients with acute myocardial infarction and no previous diagnosis of diabetes mellitus: a prospective study. Lancet 2002; 359: 2140-4.

9. Bartnik M, Malmberg K, Norhammar A, Tenerz A, Ohrvik J, Ryden $L$. Newly detected abnormal glucose tolerance: an important predictor of long-term outcome after myocardial infarction. Eur Heart J 2004; 25: 1990-7.

10. Klein R. Hyperglycemia and microvascular and macrovascular disease in diabetes. Diabetes Care 1995; 18: 258-68.

11. Noordzij PG, Boersma E, Schreiner F, et al. Increased preoperative glucose levels are associated with perioperative mortality in patients undergoing noncardiac, nonvascular surgery. Eur $\mathbf{J}$ Endocrinol 2007; 156: 137-42.

12. Fleisher LA, Beckman JA, Brown KA, et al. (2007) ACC/AHA guidelines on perioperative cardiovascular evaluation and care for noncardiac surgery: a report of the American College of Cardiology/American Heart Association Task Force on Practice Guidelines (Writing Committee to Revise the 2002 Guidelines on Perioperative Cardiovascular Evaluation for Noncardiac Surgery): developed in collaboration with the American Society of Echocardiography, American Society of Nuclear Cardiology, Heart Rhythm Society, Society of Cardiovascular Anesthesiologists, Society for Cardiovascular Angiography and Interventions, Society for Vascular Medicine and Biology, and Society for Vascular Surgery. Circulation 116: e418-e499

13. Akhtar S, Barash PG, Inzucchi SE. Scientific principles and clinical implications of perioperative glucose regulation and control. Anesth Analg 2010; 110: 478-97.

14. Moghissi ES, Korytkowski MT, Di Nardo M, et al. American Association of Clinical Endocrinologists and American Diabetes Association consensus statement on inpatient glycemic control. Endocr Pract 2009; 15: 353-69.

15. Finfer S, Bellomo R, Boyce N, et al. A comparison of albumin and saline for fluid resuscitation in the intensive care unit. $\mathrm{N}$ Engl $\mathrm{J}$ Med 2004; 350: 2247-56.

16. Brunkhorst FM, Engel C, Bloos F, et al. Intensive insulin therapy and pentastarch resuscitation in severe sepsis. N Engl J Med 2008; 358: 125-39.

17. Putney $J W$, Biancri CP. Site of action of dantrolene in frog sartorius muscle. J Pharmacol Exp Ther 1974; 189: 202-12.

18. Subramaniam B, Panzica PJ, Novack V, et al. Continuous perioperative insulin infusion decreases major cardiovascular events in patients undergoing vascular surgery: a prospective, randomized trial. Anesthesiology 2009; 110: 970-7.

19. Abdelmalak B, Maheshwari A, Mascha E, et al. Organization Design of the Dexamethasone, Light Anesthesia, Tight Glucose Control (DeLiT) Trial: a factorial trial evaluating the effects of corticosteroids, glucose control, depth-of-anesthesia on perioperative inflammation, morbidity from major non-cardiac surgery. BMC Anesthesiol 2010; 10: 11. 